\title{
COMMUNICABLE DISEASES REPORT, NSW, FOR FEBRUARY 2004
}

\section{TRENDS}

Reports of communicable disease received through to the end of February 2004 in NSW are summarised in Table 3 and Figure 1. Notifications of the mosquito-borne Ross River virus and Barmah Forest virus infections increased in February, mainly in the north of the State. Notifications of cryptosporidiosis remain high, although may have peaked in January. Although the numbers have not increased statewide, cases in February appear to be more widespread than in January. Investigations by public health units, including interviews with patients, have not identified any likely common sources of infection among cases. Nonetheless, because the causal Cryptosporidium parasites can easily contaminate swimming poolsthereby placing other swimmers at risk of infection-patients with this infection, as well as anyone with diarrhoea in the previous week, should not enter a swimming pool.

For updated information, visit www.health.nsw.gov.au and click on the link to infectious diseases.

\section{LISTERIA IN SANDWICHES}

In late January, a batch of turkey and cranberry sandwiches was tested for bacterial contamination, as part of a food service quality assurance program by an area health service. In mid-February, the testing laboratory reported that it had identified Listeria monocytogenes bacteria in two of the sandwiches. No quantification was done of the amount of Listeria bacteria present. The food service reported this result to staff of their local public health unit, who determined the appropriate course of action.

The sandwiches were part of a batch of up to 5,000 made each day by a private company and distributed to a range of commercial and other facilities, including the hospitals within the area health service. The staff of the area health service reported that the sandwiches from the batch would have been served to patients and staff in several hospitals, but any uneaten sandwiches had been discarded 24 hours after delivery (which is routine). The food inspector at a second public health unit investigated the manufacturing premises, and could find no likely sources of contamination. Both the manufacturer and the area health service reported that quality assurance procedures had not identified any previous positive Listeria results in sandwiches produced by the manufacturer.

L. monocytogenes bacteria are commonly found in the environment, as well as in raw and processed foods. The bacteria can be carried in the gut of both animals and humans without causing symptoms and, in some studies, up to 29 per cent of healthy abattoir workers have been found to carry the bacteria without harm. ${ }^{1}$ Illness following infection is rarely reported. In one European study of 116 pregnant women who were shown to be carrying the organism in their gut, 86 of 87 meconium (the fluid associated with the newborn baby) samples were clear of infection. $^{2}$

In NSW, between 10 and 28 patients have been reported with listeriosis each year since 1991. When illness does occur, it can either present as gastroenteritis, or invasive disease (including septicaemia or meningo-encephalitis, especially in newborn babies, or as abortion in pregnant women). Risk factors for invasive disease include being pregnant, a neonate, immuno-suppressed, or elderly. Outbreaks of listeriosis have been linked to contaminated foods such as milk, soft cheese, coleslaw, pate and processed meats, as well as oil used to bathe neonates. ${ }^{1}$

In response to the finding of $L$. monocytogenes in the sandwiches, NSW Health convened an advisory panel including experts in public health, microbiology, food safety, and the epidemiology of listeriosis. The panel concluded that the risk of infection for anyone who ate the sandwiches was extremely low. As a precaution, however, it was recommended that the doctors in charge of the clinical departments that received the sandwiches at the affected hospitals be advised, and that they should consider the possibility of listeriosis in any patients presenting with symptoms. No infections associated with eating sandwiches have been identified. One patient with listeriosis was identified from the area health service, however genetic fingerprinting of the bacteria from the patient and from the sandwiches showed that they were unrelated.

\section{References}

1. Armstrong D, Gellin BG. Listeria monocytogenes infections. Evans AS and Brachman PS (editors). Bacterial infections of humans, Epidemiology and control, 3rd edition. New York: Plenum Medical Book Company, 1998; 421-436.

2. Kampelmacher EH, Maas DE, van Noorle Jansen LM. Occurrence of Listeria monocytogenes in feces of pregnant women with and without direct animal contact. Zentralblatt für Bakteriologie, Parasitenkunde, Infektionskrankheiten und Hygiene—Erste Abteilung Originale—Reihe A: Medizinische Mikrobiologie und Parasitologie March 1976; 234(2): 23842 (Abstract).

\section{DIARRHOEA INFECTIONS DUETO SALMONELLOSIS INCREASES IN NSW}

In February, there has been a large increase in patients diagnosed with Salmonella Typhimurium infection in NSW. Salmonella infections usually cause diarrhoea, nausea, abdominal pain, fever, and headache. $S$. Typhimurium is the most commonly reported Salmonella serovar (or strain) in NSW, and in 2003 it accounted for about 50 per cent of all Salmonella in NSW. 
TABLE 1

PERCENTAGE OF FULLY IMMUNISED CHILDREN FOR FIVE SEPARATE COHORTS OF CHILDREN AGED 12 MONTHS TO LESS THAN 15 MONTHS BY AREA HEALTH SERVICE

\begin{tabular}{|c|c|c|c|c|c|}
\hline Area Health Service & 30 Mar 03 & 30 Jun 03 & 30 Sept 03 & $31 \mathrm{Dec} 03$ & 30 Mar 04 \\
\hline Central Coast & 93 & 92 & 93 & 95 & 92 \\
\hline Central Sydney & 91 & 90 & 90 & 89 & 89 \\
\hline Hunter & 94 & 95 & 93 & 94 & 95 \\
\hline Illawarra & 92 & 93 & 92 & 93 & 93 \\
\hline Northern Sydney & 90 & 91 & 91 & 90 & 91 \\
\hline South Eastern Sydney & 90 & 91 & 92 & 90 & 91 \\
\hline South Western Sydney & 91 & 90 & 91 & 90 & 91 \\
\hline Wentworth & 93 & 91 & 92 & 91 & 91 \\
\hline Western Sydney & 92 & 90 & 91 & 91 & 90 \\
\hline Far West & 93 & 88 & 91 & 93 & 88 \\
\hline Greater Murray & 92 & 94 & 93 & 93 & 93 \\
\hline Macquarie & 92 & 94 & 93 & 93 & 93 \\
\hline Mid North Coast & 90 & 89 & 90 & 91 & 89 \\
\hline Mid Western & 94 & 93 & 94 & 91 & 94 \\
\hline New England & 92 & 92 & 95 & 95 & 93 \\
\hline Northern Rivers & 85 & 84 & 85 & 84 & 85 \\
\hline Southern & 89 & 91 & 92 & 89 & 91 \\
\hline NSW & 91 & 91 & 91 & 91 & 91 \\
\hline Australia & 91 & 91 & 92 & 91 & 91 \\
\hline
\end{tabular}

\section{TABLE 2}

PERCENTAGE OF FULLY IMMUNISED CHILDREN IDENTIFIED AS ABORIGINAL OR TORRES STRAIT ISLANDER, FOR FIVE SEPARATE COHORTS AGED 12 MONTHS TO LESS THAN 15 MONTHS

\begin{tabular}{|lccccc|}
\hline & 31 Mar 03 & 30 Jun 03 & 30 Sept 03 & 31 Dec 03 & 31 Mar 04 \\
\hline NSW & 86 & 84 & 88 & 85 & 83 \\
Australia & 86 & 84 & 87 & 83 \\
\hline
\end{tabular}

$S$. Typhimurium is further discriminated by over 50 phage types, of which types 170, 9, 135, 135a, 197, and 12 are the most commonly reported.

To further characterise the nature of this outbreak, we examined the data for all cases reported to us in January and February by the Centre for Infectious Diseases and Microbiology Laboratory Services at the Institute of Clinical Pathology and Medical Research. By late February, 187 patients had been reported with $S$. Typhimurium infections in 2004. Patients were distributed across all area health services. Males accounted for 54 per cent, and the age groups 10-19 years and 2029 years accounted for 39 per cent of all patients.

Seasonal peaks of salmonellosis are expected in the warmer months, possibly associated with poor food storage and the consequent increased load of Salmonella bacteria in food. Salmonella infection can be prevented by: keeping foods refrigerated before use, thoroughly washing hands after using the toilet and before preparing food, not preparing food for others while ill, and not contaminating ready-to-eat foods with raw foods. To identify a common source of these infections, NSW Health is interviewing cases of $S$. Typhimurium reported after 16 February. To date, no obvious source of the outbreak has been identified.

\section{QUARTERLY REPORT: AUSTRALIAN CHILDHOOD IMMUNISATION REGISTER}

Table 1 details the percentage of fully immunised children aged 12 months to less than 15 months in each area health service, reported by all service providers.

These data refer to five different cohorts of children whose age has been calculated 90 days before data extraction. The information contained in each of the reports has been extracted from the Australian Childhood Immunisation Register (ACIR) and may not reflect actual coverage due to under-reporting. Table 2 details the percentage of fully immunised children identified as Aboriginal or Torres Strait Islander in New South Wales for the same cohort, reported by all service providers. 


\section{IMPROVING OUR UNDERSTANDING OF, AND THE CONTROL OF, COMMUNITY METHICILLIN- RESISTANT STAPHYLOCOCCUS AUREUS: DEVELOPMENT OF A TRIAL SENTINEL SURVEILLANCE PROGRAM INTHE FAR WEST OF NEW SOUTH WALES}

Catherine Kennedy and Hugh Burke

Far West Population Health Unit

Far West Area Health Service

\section{Barbara Telfer}

NSW Public Health Officer Training Program

NSW Department of Health

\section{Jeremy McAnulty \\ Communicable Disease Branch \\ NSW Department of Health}

Phil Lambie and Andrew Moreton

General Practitioners

Outback Division of General Practice

\section{Iain Gosbell}

Staphylococcal Reference Facility

South Western Area Pathology Service

This article describes the background and methods used by the community methicillin-resistant Staphylococcus aureus sentinel surveillance program that is currently being piloted in the Far West Area Health Service.

\section{Background}

Staphylococcus aureus is a bacterium commonly found on the skin and in the nose. ${ }^{1,2,3}$ This usually harmless organism can on occasion cause serious illness and death., ${ }^{2,3}$ $S$. aureus has the ability to become resistant to most classes of antibiotics used in the treatment of infections. Strains resistant to methicillin, known as methicillin-resistant Staphylococcus aureus (MRSA), emerged in the 1960s and are now a common cause of infection in healthcare institutions around the world (healthcare-associated MRSA). ${ }^{1,2}$ Since the 1980s, reports from the United States, Canada, Europe, New Zealand, and Australia indicate that MRSA can also be acquired in the community by people who have not had contact with a healthcare institution. ${ }^{1,4-17}$ Though the definition of community MRSA, previously termed 'community-acquired MRSA', varies in the literature, and its epidemiology is poorly understood, these reports suggest that community MRSA is becoming more prevalent.

Risk factors for acquisition of strains of healthcare associated MRSA include the extremes of age (young and old), surgery, use of indwelling devices or catheters, previous exposure to antibiotics, haemodialysis, admission to intensive care, and chronic diseases. ${ }^{2,3}$ Many patients with community MRSA lack these risk factors. In recent times, a set of risk factors for the acquisition of community MRSA, which are different to those for healthcare-associated MRSA, have emerged: intravenous drug use, low socioeconomic status, engaging in contact sports, being an inmate of a correctional facility, and being a man who has sex with men. However, many patients with community MRSA lack these risk factors as well.

S. aureus is spread through direct contact with a person who is infected with or who is a carrier of the bacterium. ${ }^{4}$ Community MRSA infections usually manifest as skin lesions such as boils, impetigo, abscesses, and carbuncles. ${ }^{3}$ More serious MRSA infections can cause cellulitis (infection of tissue below the skin), osteomyelitis (infection of bone), pneumonia (infection of the lungs), and bacteraemia (infection of the blood). ${ }^{2,3}$ Persons with draining lesions or purulent discharge from sites of infection, such as boils, are the most likely sources of outbreaks. ${ }^{3}$ Autoinfection (self-infection) is reported to account for one-third of all community MRSA infections. ${ }^{3}$

In Australia, community MRSA was first detected in Western Australia, mainly among people from remote areas in the Kimberley and Goldfields regions. ${ }^{12,16,17}$ These people had not been in hospitals outside of Western Australia and were not known to carry MRSA. The strains of community MRSA first detected in Western Australia have since spread widely throughout Australia. ${ }^{18}$ In the mid-1990s, reports of community MRSA that are resistant to methicillin but not to other drugs came from Brisbane, Melbourne, and Sydney. ${ }^{15}$ Many patients were Polynesian and typical infections involved the skin and soft tissues.

The Australian Group on Antimicrobial Resistance has extensive Australia-wide data on MRSA. ${ }^{19,20}$ The 2000 survey showed that several epidemic clones constituted community MRSA in Australia: at least five strains of 'WA MRSA', the Oceania strain, the Ipswich strain, and four others. ${ }^{20}$

While measures to control the spread of community MRSA in Australia have not been identified, it has been reported that ' ... community based control programs need support for individual patient management, improved housing and hygiene, control of skin sepsis, and appropriate use of antibiotics ...' ${ }^{14}$

In 2001, the NSW Infectious Diseases Advisory Committee formed a subcommittee to make recommendations regarding surveillance and control of community MRSA. Members of this subcommittee included staff from public laboratories, the Communicable Diseases Branch of the NSW Department of Health, the Far West Population Health Unit (FWPHU), and the South Eastern Sydney Public Health Unit. A preliminary recommendation made by the subcommittee was to develop and pilot a simple sentinel surveillance program for community MRSA among general practitioners. 


\section{Pilot community MRSA sentinel surveillance program}

Due to concern expressed by clinicians from the Far West Area Health Service over increasing numbers of local residents presenting with purulent skin infections, local general practitioners and the FWPHU agreed to pilot a community MRSA sentinel surveillance program. Staff from the FWPHU, the Communicable Diseases Branch of the NSW Department of Health, local general practitioners, the local laboratory, and South Western Area Pathology Service (SWAPS) have collaborated to develop the pilot program.

The aims of the community MRSA sentinel surveillance program are to:

- determine what proportion of people presenting to local general practitioners with skin infections had community MRSA;

- describe the epidemiology of community MRSA among patients seen by local general practitioners;

- establish acceptability of the sentinel surveillance program with local general practitioners;

- evaluate the sensitivity of the sentinel surveillance program and its findings;

- make recommendations of what further steps need to be taken in understanding the epidemiology of community MRSA and its prevention and control.

\section{Methods}

All patients who attend participating general practitioners with a skin infection or other suspected community MRSA infections were considered for inclusion in the surveillance program. General practitioners were asked to swab skin infections and collect de-identified clinical and demographic data. To protect the privacy of patients, a code for their family name and date of birth was used to identify them on a one-page general practitioner data collection form, which was designed for the pilot program. The information collected on this form was necessary to link the data collected by general practitioners with pathology results.

Patient information collected by general practitioners included date of birth, sex, Aboriginal and Torres Strait Islander status, residential address, date of onset, location of infection, type of infection, and data of swab or sample collection. Completed copies of the general practitioner data collection form were to be sent to the FWPHU, and another copy was placed in the medical record notes of patients.

Swabs collected by participating general practitioners are sent to the local laboratory and tested for MRSA. When found positive for MRSA, samples were forwarded to SWAPS for phage typing. Pathology results from SWAPS were then forwarded to the FWPHU. The FWPHU then matched the pathology results to the data collected by general practitioners using the patient's code for name and date of birth.

The FWPHU only received notification of MRSA positive results and managed the collection, analysis, and interpretation of data and report findings with the assistance of the Communicable Diseases Branch.

\section{General Practitioner Intervention}

Participating general practitioners discussed skin infections and how to prevent their spread with the patients under surveillance. A fact sheet on boils and impetigo was designed for use by general practitioners for dissemination to patients. If a patient was found to have community MRSA, the general practitioner requested the patient to come back for treatment, and used that opportunity to talk with the patient about MRSA and its prevention. A second fact sheet on MRSA was designed to facilitate this process. Treatment for patients found to have community MRSA infections was to include clindamycin or cotrimoxazole, assuming isolates are susceptible.

\section{Evaluation}

Mid-pilot and end-of-pilot reviews of general practitioner notes will be undertaken to evaluate the sensitivity of the surveillance system in identifying MRSA cases. Staff of the FWPHU will attend general practitioner surgeries and audit patient notes for suspected skin infections, rate of swabbing and pathology results. A random sample of cases will be interviewed to assess appropriateness and uptake of patient education, and barriers to preventing the spread of community MRSA. This interview process will be done by the FWPHU as part of the evaluation of the pilot and fact sheets.

\section{Ethics approval}

The Western NSW Human Research Ethics Committee was provided with a report of the proposed MRSA sentinel surveillance program. They supported its implementation and agreed that as the pilot program was part of public health action it did not require ethical approval. Future projects will need to collect more information on risk factors and the relative value of interventions for community MRSA and are therefore likely to require an ethics application and approval.

\section{Dissemination of findings}

It is anticipated that the findings of the pilot will be completed by mid-year. The FWPHU will write up the findings of the pilot and its evaluation with assistance from the Communicable Diseases Branch. The findings will be communicated to the wider public health network in NSW and to the Infectious Diseases Advisory Committee 
subcommittee on community MRSA, to inform any future action regarding the surveillance and control of community MRSA.

\section{Acknowledgements}

The authors wish to thank the participating general practitioners and the laboratory staff at Institute for Clinical Pathology and Medical Research and the South Western Area Pathology Service for their contributions to this pilot.

\section{References}

1. Chambers HF. The Changing Epidemiology of Staphylococcus aureus? Emerg Infect Dis 2001; 7(2): 178-182.

2. Ruben FL, Muder RR. Staphylococcal Infections. Evans AS and Brachman PS (editors). Bacterial infections in humans: Epidemiology and control. 3rd edition. New York and London: Plenum Medical Book Company, 1998; 657-672.

3. Chin J. Control of Communicable Diseases Manual. 17th edition. Washington DC: American Public Health Association, 2000.

4. Garner JS, Jarvis WR, Emori TG, et al. CDC definitions for nosocomial infections. Am J Infect Control 1988; 16: 128-140.

5. Gosbell IB, Mercer JL, Neville SA, Crone SA, Chant KG, Jalaludin BB, Munro R. Non-multiresistant and multiresistant methicillin-resistant Staphylococcus aureus in communityacquired infections. Med J Aust 2001; 174: 627-630.

6. Groom AV, Wolsey DH, Naimi TS, Smith K, Johnson S, Boxrud D, Moore KA, Cheek JE. Community-acquired methicillin-resistant Staphylococcus aureus in a rural American Indian community. JAMA 2001; 286(10): 1201-1205.

7. Nimmo GR, Schooneveldt J, O'Kane G, McCall B, Vickery A. Community acquisition of gentamicin-sensitive methicillinresistant Staphylococcus aureus in Southeast Queensland, Australia. J Clin Microbiol 2000; 38(11): 3926-3931.

8. Akram J, Glatt AE. True community acquired methicillinresistant Staphylococcus aureus bacteremia. Infection Control and Hospital Epidemiology 1998; 106-109.

9. Wagenvoort JHT, Kepers-Rietrae M. Methicillin resistant Staphylococcus aureus (MRSA) as a community strain. Eurosurveillance Monthly Archives 1997; 2(2): 96-97.
Available online at www.eurosurveillance.org/em/v02n12/ 0212-222.asp. Accessed 26 February 2003.

10. Salmenlinna A, Lyytikainen O, Vuopio-Varkila J. Communityacquired methicillin-resistant Staphylococcus aureus, Finland. Emerg Infect Dis 2002; 8(6): 602-607.

11. Herold BC, Immergluck LC, Maranan MC, Lauderdale DS, Gaskin RE, Boyle-Vavra S, Leitch CD, Daum RS. Community-acquired methicillin-resistant Staphylococcus aureus in children with no identified predisposing risk. JAMA 1998; 279(8): 593-598.

12. Riley TV, Pearman JW, Rouse IL. Changing epidemiology of methicillin-resistant Staphylococcus aureus in Western Australia. Med J Aust 1995; 163: 412-414.

13. Maguire GP, Arthur AD, Boustead PJ, Dwyer B, Currie BJ. Emerging epidemic of community-acquired methicillinresistant Staphylococcus aureus infection in the Northern Territory. Med J Aust 1996; 164(12): 721-23.

14. Maguire GP, Arthur AD, Boustead PJ, Dwyer B, Currie BJ. Clinical experience and outcomes of community-acquired and nosocomial methicillin-resistant Staphylococcus aureus in a Northern Australian hospital. J Hosp Infect 1998; 38(4): 273-81.

15. Collignon P, Gosbell I, Vickery A, Nimmo G, Stylianopoulos T, Gottlieb T. Community-acquired meticillin-resistant Staphylococcus aureus in Australia. Australian Group on Antimicrobial Resistance [letter]. Lancet 1998; 352: 145-146.

16. Udo EE, Pearman JW, Grubb WB. Genetic analysis of community isolates of methicillin-resistant Staphylococcus aureus in Western Australia. J Hosp Infect 1993; 25: 97-108.

17. Pearman JW. MRSA: The pathogen hospitals dread. Microbiol Aust 1996; 29-31.

18. Workshop on MRSA Typing: Applications of methods in an MRSA typing laboratory. Antimicrobials 2003, Australian Society for Antimicrobials 4th Annual Scientific Meeting, May 1-5 2003, Melbourne, Australia, 2003.

19. Symposium on AGAR Staphylococcus Awareness Program: Community MRSA. Antimicrobials 2003, Australian Society for Antimicrobials 4th Annual Scientific Meeting, May 1-5, Melbourne, 2003.

20. Symposia G. NORSA and MORSA in the Community. Epidemiology: The AGAR Data. Antimicrobials 2002 Australian Society for Antimicrobials 3rd Annual Scientific Meeting, February 28 to March 2, Sydney, 2002. W 
FIGURE 1

REPORTS OF SELECTED COMMUNICABLE DISEASES, NSW, JANUARY 1998 TO FEBRUARY 2004, BY MONTH OF ONSET

Preliminary data: case counts in recent months may increase because of reporting delays. Laboratory-confirmed cases only, except for measles, meningococcal disease and pertussis $\mathrm{BFV}=$ Barmah Forest virus infections, RRV = Ross River virus infections $\mathrm{LI}=$ Legionella longbeachae infections, $\mathrm{L} p=\mathrm{L}$. pneumophila infections Gp $C$ and $G p B=$ disease due to serogroup $C$ and serogroup B infection, other/unk $=$ other or unknown serogroups

\section{cases}

\begin{tabular}{|cc|}
\hline \multicolumn{2}{|c|}{ Dec 03-Feb 04 } \\
Male & $53 \%$ \\
$<5$ & $0 \%$ \\
$5-24$ & $13 \%$ \\
$25-64$ & $78 \%$ \\
$65+$ & $9 \%$ \\
Rural & $92 \%$ \\
\hline
\end{tabular}
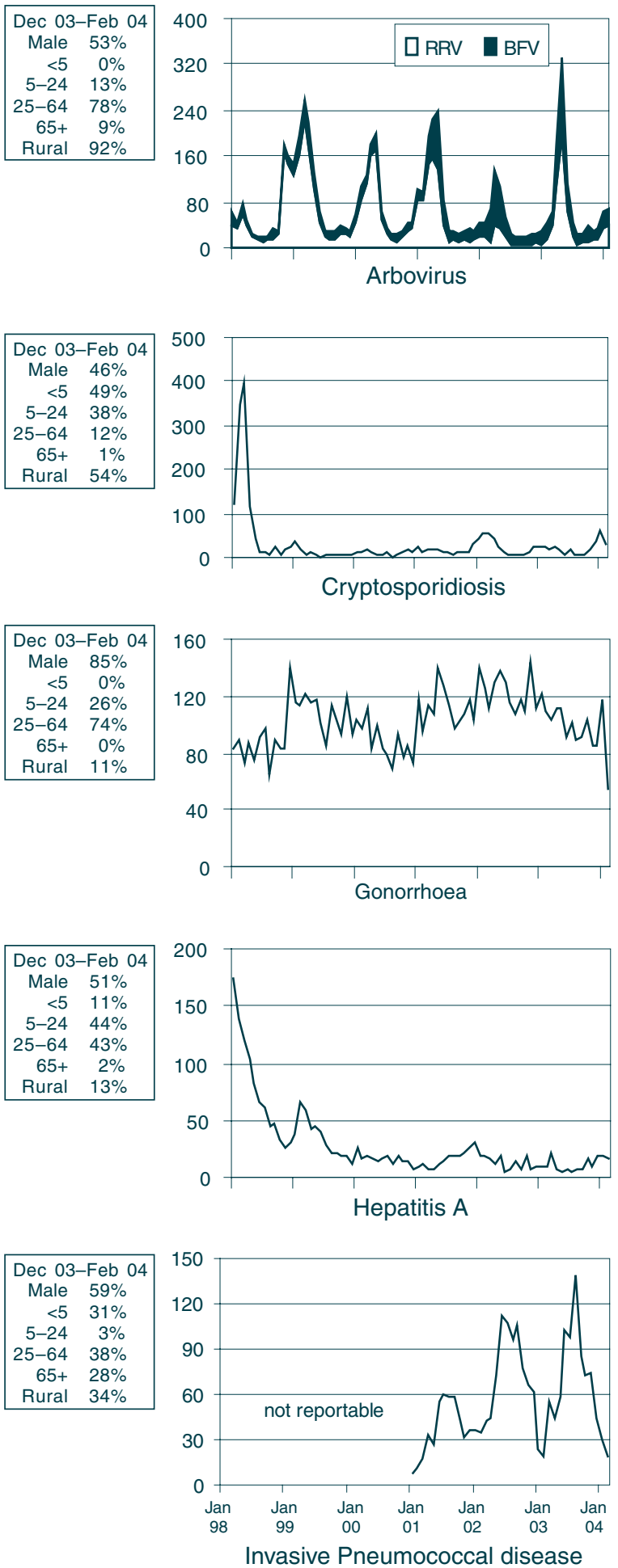

cases

\begin{tabular}{|cc|}
\multicolumn{2}{|c|}{ NSW population } \\
Male & $50 \%$ \\
$<5$ & $7 \%$ \\
$5-24$ & $28 \%$ \\
$25-64$ & $52 \%$ \\
$65+$ & $13 \%$ \\
Rural $^{*}$ & $42 \%$ \\
\hline
\end{tabular}
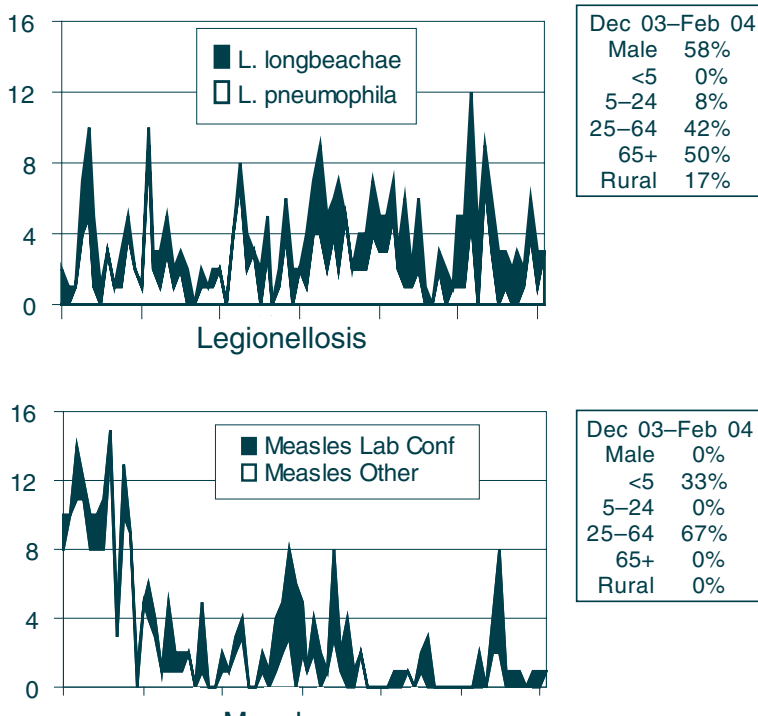

Measles
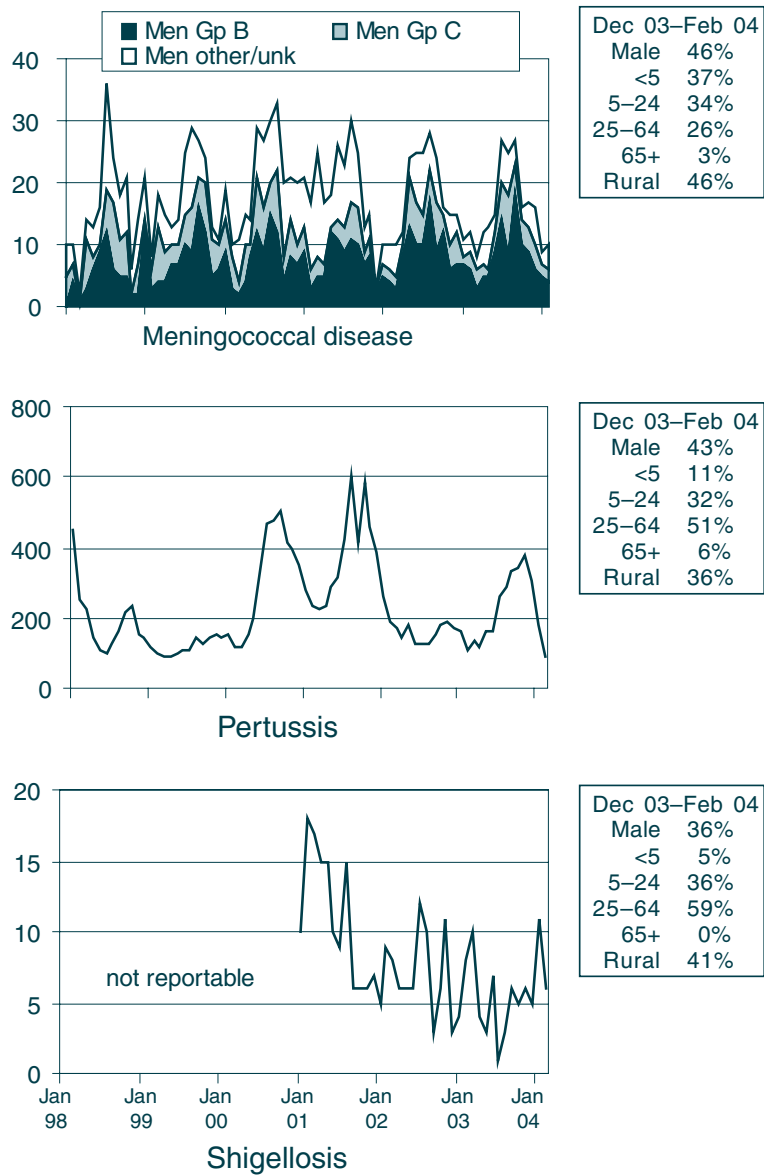


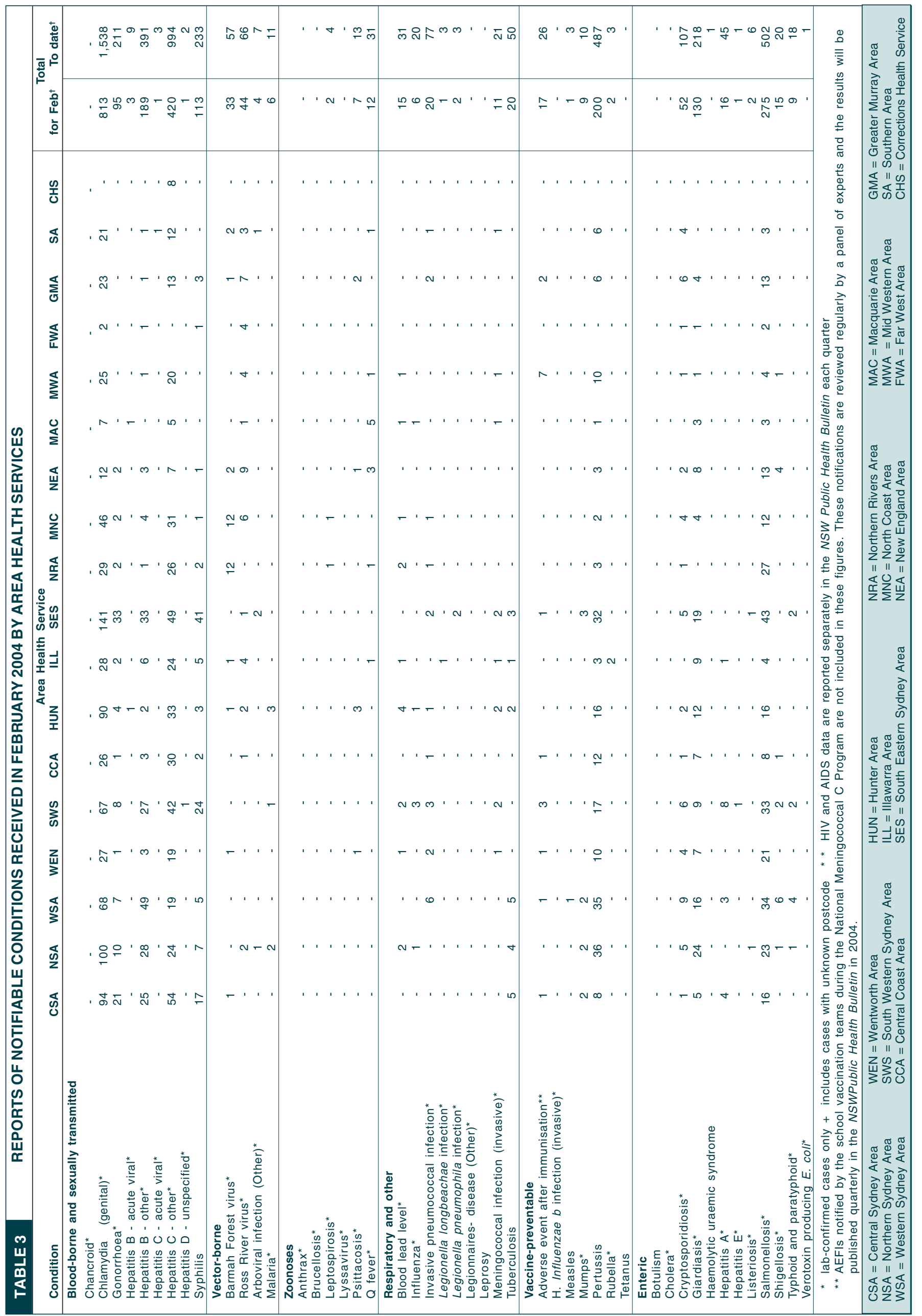

